\title{
Of headlines \& headlinese: Towards distinctive linguistic and pragmatic genericity
}

\section{Shaeda Isani}

\section{(2) OpenEdition \\ 1 Journals}

Electronic version

URL: http://journals.openedition.org/asp/2523

DOI: 10.4000/asp.2523

ISSN: 2108-6354

\section{Publisher}

Groupe d'étude et de recherche en anglais de spécialité

\section{Printed version}

Date of publication: 1 November 2011

Number of pages: 81-102

ISSN: 1246-8185

\section{Electronic reference}

Shaeda Isani, «Of headlines \& headlinese: Towards distinctive linguistic and pragmatic genericity », ASp [Online], 60 | 2011, Online since 07 October 2014, connection on 02 November 2020. URL : http:// journals.openedition.org/asp/2523; DOI : https://doi.org/10.4000/asp.2523

This text was automatically generated on 2 November 2020.

Tous droits réservés 


\title{
Of headlines \& headlinese: Towards distinctive linguistic and pragmatic genericity
}

\author{
Shaeda Isani
}

1 The headline - "one of the most distinctive features of a newspaper" according to David Crystal (1987: 388) - is a form of discourse specific to the written press. It is undoubtedly one of the most creative areas of journalistic writing and, in some aspects, comparable to poetry in that it borrows extensively from linguistic features generally associated with versification. As Don P. Brown and Doug Simpson (2002), copy editor and chief headline writer respectively, claim in their recommendations to future journalists, "Headline writers have to be the best writers at the newspaper."

2 Headlines are also, according to specialists, the most widely read part of a newspaperfive times more than the body copy - since headlines are scanned not only by initial purchasers but also by the innumerable people in their immediate vicinity.

3 Arguments that the titles announced at the beginning of a TV or radio news bulletin may, to some extent, be considered as headlines are not retained in the framework of this study since they do not possess the textual, linguistic and pragmatic characteristics specific to print headline discourse.

\section{Scope of study}

4 This article reflects enquiry related to headline discourse and presents preliminary findings based on an analysis of essentially British newspapers, a choice which, if undeniably determined in part by personal culture, is nevertheless essentially due to the unique reputation of the British press in the area of headline creativity.

In spite of the abundant research on newspaper headlines and the richness of its genericity, there is a relative dearth of attempts to define the object of research. As Ingrid Mardh (1980: 14) points out in her exhaustive study of the linguistic aspects of 
headlines, "No unambiguous definition of 'headline' is known to exist. The word headline seems to be used intuitively, also in linguistic studies of headlines."

Given the textual, linguistic and pragmatic complexity of the field, it is perhaps understandable that attempts to provide a definition have confined themselves to the textual functions of headlines as "artefacts" (Graddol, cited in Bell \& Garrett 2001: 3) or "visual marks on a page" (Kress \& van Leeuwen 2001: 186), echoing the technical definition supplied by the online Newspaper Designer's Handbook: "Large type running above or beside a story to summarize its content. Also called a head."

7 Mardh (1980) herself adopts a similar minimalist approach and defines the object of her research somewhat prosaically as: "A headline is set in a size and style of type which is different from the running text. It consists of one or more decks, which also differ typographically from one another" (1980: 14).

Contrary to such approaches, in the framework of this study, the term headline is not viewed as a textual artefact. Neither is it viewed as a deck entity (superheadline, headline, subheadline and lead). The focus of study here is limited to the headline, the most visually outstanding component of the deck. Hence, in the following deck (The Economist, 20 January 2007), only the central unit comes under the scope of this discussion:

Death of the record store [in red]

Facing the music [in bold and larger font size]

Britain's music stores are being squeezed off the high street [in smaller font size and bold]

9 This article posits that, within the multifunctional and multiple umbrella genre that is generally referred to as headlines, there exist certain characteristics not common to all headlines but sufficiently recurrent in others to constitute a sub-genre which we propose to distinguish from the parent genre by the term headlinese. For illustration purposes, core reference is essentially made to contemporary editions of four "quality" British press organs, The Economist, The Guardian, The Independent and The Daily Telegraph, and supplemented by references to other news organs such as certain British tabloids and online press articles (the BBC), and an occasional American newspaper.

In a first part, we propose a theoretical framework to demonstrate the genericity of a specific sub-genre (van Dijk 1988; Swales 1990; Dor 2003; Gattani 2005) and then proceed to distinguish between the umbrella genre of "generic headlines" and the subgenre "headlinese" on the basis of a pragmatic approach and reader accessibility theories with regard to the sub-genre's defining characteristic, opacity. Finally, we explore the notion of a discourse community specific to headlinese and, in conclusion, suggest envisaging a paradigm shift which relates headlinese to other genres presenting similar characteristics.

\section{Genre}

Initially related to literary genres, genre studies are today a cross-disciplinary field which interests researchers in linguistic, rhetorical, social and even scientific disciplines. One of the most prominent contributions to non-literary genre theory is undoubtedly Swales' (1990), who studies genre as an institutionalised mediator between individual and institution principally in the framework of academic communication for applied ends. 
12 In spite of its focus on academic settings, Swales' analysis of genre, speech community and discourse community has contributed to the extension of genre theories to such non-academic and non-professional domains as skate board communities (Herino \& Isani 1994) and digital communication (Breure 2001). In the same exploratory vein, we analyse headlines as genre on the basis of the framework proposed by Swales in the following complementary definitions:

Genres themselves are classes of communicative events which typically possess features of stability, name recognition and so on. Genre-type communication events [...] consist of texts themselves (spoken, written, or a combination) plus encoding or decoding procedures as moderated by genre-related aspects of text-role and textenvironment. These processing procedures can be viewed as tasks. The acquisition of genre skills depends on previous knowledge of the world, giving rise to content schemata, knowledge of prior texts, giving rise to formal schemata, and experience with appropriate tasks. (1990: 9-10).

A genre comprises a class of communicative events, the members of which share some set of communicative purposes. These purposes are recognised by the expert members of the parent discourse community, and thereby constitute the rationale for the genre. This rationale shapes the schematic structure of the discourse and influences and constrains choice of content and style. (1990: 58)

13 These two definitions carry several areas of focus particularly relevant to our study and which relate to our field of application as shown in Table 1:

Table 1. Genre definition with regard to headlinese as a sub-genre

\begin{tabular}{|l|l|l|}
\hline \multicolumn{1}{|c|}{ Genre theory factor } & \multicolumn{1}{|c|}{ Applied factor } \\
\hline 1. & $\begin{array}{l}\text { "a class of communicative act" } \\
\text { "texts" }\end{array}$ & Headlines/Headlinese \\
\hline 2. & $\begin{array}{l}\text { "encoding or decoding procedures" } \\
\text { "processing procedures" }\end{array}$ & $\begin{array}{l}\text { Journalist/text/reader } \\
\text { interpretation }\end{array}$ \\
\hline 3. & $\begin{array}{l}\text { "the members [...] share some set of communicative } \\
\text { purposes" } \\
\text { "the expert members of the parent discourse community" }\end{array}$ & Journalists/Readers \\
\hline 4. & $\begin{array}{l}\text { "[..] shapes the schematic structure of the discourse and } \\
\text { influences and constrains the choice of content and style." }\end{array}$ & $\begin{array}{l}\text { Textual, linguistic and cultural } \\
\text { parameters of headlinese }\end{array}$ \\
\hline
\end{tabular}

14 In view of the above elements, we hope to have established the overall theoretical validity of the genre construct with regard to headlines and now propose to focus on the communicative function they seek to fulfil.

\section{Functions of headlines}

15 Van Dijk (1988) attributes a cataphoric and informative function to headlines by defining their essential function as that of summarising the content of the article they precede: 
Each news item in the press has a Headline [...] and many have a Lead, whether marked off by special printing type or not. We also have an elementary rule for them: Headline precedes Lead, and together they precede the rest of the news item. Their structural function is also clear: Together they express the major topics of the text. That is, they function as an initial summary. [...] The semantic constraint is obvious: Headline + Lead summarize the news text and express the semantic macrostructure. (1988: 53)

While van Dijk's interpretation is entirely valid with regard to the function of the headline when placed within the two or three tier architecture of the deck, it is less so with respect to the headline as an autonomous unit. Considering that visual highlighting of the headline unit through use of bolder and larger type is clearly designed to make it stand out from the rest of the deck, it may be argued that even headlines placed in a full deck enjoy a de facto autonomous status.

Today, there is broad consensus regarding the dual and competing functionality of headlines i.e., to inform and to persuade:

On the one hand, the headline should supply the reader with the main information contained in the item. On the other hand, the headline is also the opening and the most important part of the item and it is supposed not only to inform the reader, but also to persuade him/her to read the whole item. However, the editor has space constraints, as well as contextual constraints, which derive from the function of the headline in a newspaper. Hence, newspaper headlines have a special style; they are characterized by density of information and syntactic characteristics of telegraphic speech. They also contain bold expressions, polarization, exaggerations and provocative wording, and appear in bigger print and sometimes in colour. (Kronrod \& Engel 2001: 685-686)

Headline creation may therefore be considered to be subject to the three often conflicting imperatives of surface economy, information and persuasion, surface economy being the invariable around which the two fluctuating variables of information and/or persuasion must be calibrated. These functional categories may also be referred to as semantic functions when focusing primarily on information transmission, or as pragmatic functions when intended meaning and interpretation are dependent on the speaker, the addressee and other features of the context of utterance, i.e., when the headline is a sociorhetorical communicative act which requires the reader to engage and interact with text and social context to extract meaning.

Regarding headline functionality, two sets of literature, Dor (2003) and Gattani (2005) present separate but complementary analyses which may be summed up in terms of macro and micro functionality. For Dor (2003), headlines are "the negotiators between stories and readers" and have four functions: to summarise, to highlight, to attract and to select. Gattani (2005) identifies three broad macro headline functions:

The informative headline which gives a good idea about the topic of the news story; the indicative headline which addresses what happened in the news story and finally, the eye-catcher headlines which do not inform about the content of the news story but are designed to entice people to read the story. (Gattani 2005)

These complementary analyses may be divided into umbrella and macro/micro functionality. Dor's (2000: 720) premise that headlines are "negotiators between the stories and the readers" may be defined as the umbrella function of headlines, below which Gattani's analysis of headline functionality as being informative, indicative and eye-catching operate at macro-functional level, which in turn leads to Dor's four micro 
functions, to summarise, to highlight, to attract and to select, as demonstrated in Table 2:

Table 2. Levels of headline functionality

\begin{tabular}{|l|l|l|}
\hline \multicolumn{1}{|c|}{$\begin{array}{c}\text { Umbrella function } \\
\text { (Dor 2003) }\end{array}$} & \multicolumn{1}{|c|}{$\begin{array}{c}\text { Macro-function } \\
\text { (Gattani 2005) }\end{array}$} & \multicolumn{1}{c|}{$\begin{array}{c}\text { Micro-function } \\
\text { (Dor 2003) }\end{array}$} \\
\hline \multirow{2}{*}{$\begin{array}{c}\text { "Negotiators between the } \\
\text { stories and the readers" }\end{array}$} & Informative & To summarise \\
\cline { 2 - 3 } & Indicative & $\begin{array}{l}\text { To highlight } \\
\text { To enable selection }\end{array}$ \\
\cline { 2 - 3 } & Eye-catching & To attract \\
\hline
\end{tabular}

21 Caught between the antonymic constraints of textual, informative and persuasive imperatives, headlines offer considerable variation in degrees of overlapping or leaning towards one or the other. The Independent of 19 February 2007 provides a sampling of all three categories. While the semantics and syntax of the front page title itself lean towards the informative ("Police chief calls for heroin to be available on the NHS"), the textual approach privileges the "eye-catching" with the 4 -line $3 \mathrm{~cm}$ title spread across $2 / 3$ of the front page against a bright turquoise background, a quasi absence of any competing text and a picture of a syringe, spoon and white powder. Page 3, on the other hand, is dominated by a title which privileges the persuasive approach (appeal to humour, use of a risqué semantic register and punning): "Chinese celebrate the lucky swines born in the Year of the Pig".

\section{Generic Headlines}

An important but relatively unknown fact concerning headlines is that they are not written by the journalist whose name figures in the by-line, as Bell, himself an editor and journalist, underlines in his analysis of media language production:

Material other than 'body copy' (the continuous text of a news story) is usually generated by non-journalists: illustrations editors write captions to photographs, and subeditors write headlines. (1993: 40-41)

Sub-editors, and/or a team working around the sub-editor, design headlines with surface and attention attracting constraints in mind. More surprisingly, they work with little reference to or collaboration with the journalist who authored the news story and, as a result, are not infrequently reproached with creating titles which have little or no bearing with the content they are intended to announce. As such, a headline may be considered both a multi-author and fostered text.

Headline characteristics may be broadly analysed as surface, linguistic and pragmatic. Given the extensive literature existing on the subject, we propose to limit ourselves to a brief overview of the main characteristics.

\subsection{Surface characteristics}

On the surface level, headlines are artefacts fashioned and produced by surface economy constraints on the one hand, and available technology on the other. However, as textual artefacts, they also serve an important pragmatic function, the "eyecatching" function evoked by Gattani (2005). In the context of this study, however, the difference we seek to establish between headlines as a genre and headlinese as a sub- 
genre does not reside at this visual level of text design, type face, font size, columns, place, colour, etc., but focuses on the intrinsic language component of headlines.

\subsection{Linguistic characteristics}

Academic enquiry has predominantly focused on the linguistic characterisation of headlines. This is understandable given that the layout economy constraints which mould its textuality have produced profound and striking linguistic repercussions resulting in a characteristic elliptical and telegraphic grammatical style, referred to by Halliday (1967) as "economy grammar".

Research in this area (Mardh 1980, van Dijk 1988) has amply analysed and described the distinctive linguistic features and strategies used in the linguistic culling which underlies headline text. Among the predominantly recurring elements are the omission of articles, nominalisation, use of present tense (as in the famously erroneous 3 November 1948 Chicago Daily Tribune headline, "Dewey defeats Truman"), use of the verb 'be', omission of conjugation, extensive use of metaphors ("Minnows swimming alongside whales as large and small flood fast-growing sector" - The Financial Times, 19 February 2007), use of obsolete lexical items such as "bid", "probe", "assail", "toll", "pledge", "axe", "plea", "irk", "ire", "mull", etc., ("Probe into industry welcomed by politicians and trade unions"- The Daily Telegraph, 7 March 2007), extensive use of acronyms and abbreviations ("How Ab Fab changed my life" - The Daily Telegraph, 7 March 2007), etc. Alliteration, assonance, punning, clichés, distortion of well-known catch-phrases (The Daily Mirror's "Who do you think you are, Mr Milosevic?" (7 April 1999), referring to a popular British World War II song, "Who do you think you are, Mr Hitler?), colloquialisms, etc., are also hallmark traits of headline creativity.

\subsection{Pragmatic characteristics}

In spite of the abundant literature on newspaper headlines covering a wide range of theoretical and empirical areas, surprisingly, there is comparatively little which deals with the headline as a communicative act (Dor 2003: 696).

In a pragmatic approach the primary focus shifts from the headline as a purely linguistic phenomenon to the headline as a communicative act which seeks to "build a relational structure" (van Dijk 1988: 86) by engaging with the reader through the creation of interpretive dynamics generated by deviation and retention of information. In this perspective, analysis is based largely on reception theories and as such focuses on the reader, the context and the decoding processes involved rather than on the language per se. In other words, informative headlines are content-centred whereas pragmatic headlines are reader-centred, and as such relate closely to Chovanec's (2003) analysis of the "ideational" and "interpersonal" functions of headlines.

of particular interest in the pragmatic perspective is the primacy awarded to the "attraction" function of the headline by the use of strategies designed to resist comprehension through carefully cultivate mystification and unintelligibility, deliberately flouting Grice's Co-operative Principle and three of the four accompanying maxims, quantity, relation and manner, ${ }^{2}$ deemed necessary to ensure rational exchanges. Such pragmatic strategies result in elliptical, obscure and opaque text calculated to arouse curiosity rather than to inform, and thus provoke or lure the 
reader into reading the ensuing, perhaps more prosaic text. An emblematic illustration of this type of pragmatic approach to headline writing is the March 9, 2004 front page headline from The Guardian, "No more bobbin' for the red, red robin", followed by a lowinterest story relating the killing of an American robin present in Britain by a sparrowhawk.

We note in this context that the numerous guidelines published by newspapers regarding good journalistic style consistently and consensually preach the good word about the informative, clear and precise qualities of good journalistic text. Given the recurrent frequency of elliptical headlines, it is clear that journalists tend not to practice what they preach as far as headlines are concerned and that accessibility is regularly and intentionally sacrificed on the altar of special effects.

It is this pragmatic function that constitutes the variable which distinguishes headlines from headlinese. Headlines which privilege the pragmatic approach and the related "eye-catching" or "curiosity-arousal" objective do so by producing obscure referents which will resist comprehension. It is this category of headline that we seek to establish as a specific sub-genre. Though this pragmatic function is also assumed by other textual and semiotic aspects of newspapers, the scope of this study is concerned with language used as an attention-attracting strategy to engage with and challenge the reader's accessibility skills and cognitive environment.

\section{Headlinese: a sub-genre}

33 According to Mardh (1980: 13) the term "headlinese" first originated in a journalistic hand-book written in 1933 by two New York Times journalists, R. E. Garst and T. M. Bernstein, entitled "Headlines and Deadlines". If Mardh does indeed specify that the term was initially used pejoratively to designate "strange speech that corrupts good English" for the purposes of her own analysis of "the grammar of English front page headlines", she desemanticises the term "to denote simply the language used in headlines." (1980: 13).

In spite of the inevitable pejorative associations such a move risks generating "journalese, jargon and gobbledegook" to quote part of the sales argument used by The Economist to promote its Style Guide - we would like to rehabilitate the term "headlinese" to highlight the genericity of a particular type of discourse.

Elliptical headlines are generally considered the hallmark of the British popular press, the so-called tabloids. As such, headlinese is often perceived as an inferior genre and relegated to the previously mentioned status of "gobbledegook". It is certainly true that British tabloids have a particularly strong tradition of provocative headlines and amongst the most memorable are certainly three legendary Sun headlines - "Gotcha" (1982), "Up yours Delors" (1990) and "Super Calley Go Ballistic Celtic Are Atrocious" (2000) ${ }^{3}$ which today enjoy quasi-cult status. In spite of their dubious taste, journalist Bill Hagerty, in an Independent on Sunday article entitled "The Media: The Tabloids and the Headlines that Say it All" (31 July 2005), rises in defence of tabloid headlines:

Those who consider that a vastly superior form of newspaper journalism is achieved by what until recently could be described as the broadsheet world might argue that coming up with tabloid headlines is no big trick. Writing a headline that remains seared in the reader's memory long after the story it sat on has become history is a very big trick indeed. 
ical headlines, however, are by no means the monopoly of the tabloid press and may be found in the quality press as well - albeit in a less popular register in keeping with the audience targeted - as evidenced by the elusive Daily Telegraph headline, "England is the country that 'dare not speak its name"" (online 17 October 2004). In the same vein, The Economist is well known for its penchant for elliptical and "trick" headlines, as for example, "MOBO phobic" (4 September 2004) or "Breaking the Ice" (21 August 2004). ${ }^{4}$

\subsection{Headlinese genericity}

As seen, headlinese genericity is essentially characterised by its pragmatic function Van Dijk's (1988) work on news discourse carries an interesting analysis in terms of pragmatic speech acts. The focus, however, is on body copy. If initially van Dijk perceives only an assertive function to news text - "Since news discourse nearly exclusively consists of assertions (and not promises or threats), a pragmatic description would not yield the conditions necessary for the appropriate accomplishment of assertions" (1988: 26) - his position evolves towards a more perlocutionary interpretation:

In traditional pragmatic jargon, our speech acts should not only have illocutionary functions but also perlocutionary effects. In terms of rhetoric or of the study of speech communication, this means that we are involved in a process of persuasion. In news discourse, it is not merely a question of being understood but also of being accepted as the truth or at least as a possible truth. (1988: 82)

In contrast to van Dijk's cautious approach, Develotte and Rechniewski (2001) see a more omnipresent pragmatic function in headlines:

It is difficult to draw a clear line between an informational headline and one which has a pragmatic function since much depends on the context and the readership. [However,] headlines such as "Boycott could help turn deficit round" [...] can be taken as simply informational, or can be seen as adding to pressure for such a boycott, presented implicitly as a patriotic and commercially sound act. <http:// wjfms.ncl.ac.uk/tles.htm>

Transposed to the domain of headlinese, the perlocutionary or persuasive functionality of the text becomes clear: to persuade the reader to read the news story through use of linguistic manipulation and decontextualisation designed to resist comprehension and prod, lure and incite the reader into reading the following body copy.

In the context of conventional cooperative discourse, to facilitate addresser/addressee exchange, the addresser calibrates his discourse on the premise of a pre-supposed cognitive environment and mental representations with regard to knowledge of the world, scientific theories, religious beliefs, experiential background, culture, etc. Such is the function of headlines. Headlinese, inversely, functions on the premise of a presupposed absence of the mental schemata needed to decode the message. To this effect, Crystal provides two contrastive headlines that help illustrate the distinction we seek to make:

At one extreme we find such plain, unemotional wordings as Christmas unemployment total at record level. At the other, we find such dramatic and, out of context, unintelligible items as Crash, bang, wallop! or Oh yes she is! (1987: 388)

We posit that since this cultivated unintelligibility is not a characteristic common to all headlines but represents, nevertheless, a significantly recurrent phenomenon in a substantial body of headlines, it may be admitted as the defining nucleus of a headline 
sub-genre. As such, we propose henceforth to refer to headlines in general as generic headlines and to those headlines designed to function on the pragmatic level of engaging with the reader's interpretative processes, as headlinese. In the following analysis of the sub-genre, we propose to focus on the predominant generic factor of opacity.

\subsection{Degrees of headlinese opacity}

Like all "rich" genres, the opacity genre factor is present in headlinese on a variable scale of intensity. In a prototypical approach inspired by the theories of reader accessibility initially proposed by Ariel (1988), the semantic (informative)/pragmatic (opaque) equation may be analysed on a scale of three degrees, low, intermediate and high: the lower the comprehension resistance, the higher the semantic design; the more informative the headline, the lower the challenge to reader accessibility, and inversely, the greater the comprehension resistance, the higher the pragmatic design, the less informative the headline and the higher the challenge to reader accessibility.

Ariel's scale of low, intermediate and high reader accessibility was initially designed to apply to generic headlines. Hence, low reader accessibility would apply to semanticorientated, explicitly informative headlines requiring little decoding effort on the reader's part, such as, for example, the following headline from The Guardian Weekly dated 4 June 2004: "Boy used internet to plot his own murder", while high reader accessibility would apply to headlines such as the famous 1980 New York Daily News headline "Sick transits glorious Monday". 5

To what extent may Ariel's scale be adapted to headlinese? To demonstrate its relevance, in a 2004 informal survey, a panel of six faculty members, all native and near native speakers of British English, were presented with a corpus of 50 samples of headlinese from recent editions of wide-circulation British and American newspapers with a view to classifying the headlines (presented as independent units) into the three categories suggested by Ariel. In spite of inevitable and expected divergences, Table 3 presents a sampling of some of the elements that met with consensual classification.

Table 3. Degrees of headlinese accessibility

\begin{tabular}{|c|c|c|}
\hline $\begin{array}{l}\text { Low reader accessibility } \\
\text { (Semantic/informative) }\end{array}$ & Intermediate reader accessibility & $\begin{array}{c}\text { High reader accessibility } \\
\text { (Pragmatic/opaque) }\end{array}$ \\
\hline $\begin{array}{l}\text { "EU topia is over - join the } \\
\text { real world" - The Guardian } 28 \\
\text { Sept. } 2004\end{array}$ & $\begin{array}{l}\text { "Too few women at the top is not } \\
\text { just a science problem" - The } \\
\text { Guardian } 12 \text { Feb. } 2004\end{array}$ & $\begin{array}{l}\text { "Grotty Givens"- The } \\
\text { Economist } 17 \text { April } 2004\end{array}$ \\
\hline $\begin{array}{l}\text { "Time to trim our wastelines" } \\
-B B C \text { News Online } 27 \text { Sept. } 2004\end{array}$ & $\begin{array}{l}\text { "Oil hits } 50 \text { on supply worries"- The } \\
\text { Washington Post } 28 \text { Sept. } 2004\end{array}$ & $\begin{array}{l}\text { "Tourists: by the left, } \\
\text { march" - The Economist } 29 \\
\text { July } 2004\end{array}$ \\
\hline $\begin{array}{l}\text { "Chinese walls come down" - } \\
\text { The Guardian } 11 \text { Sept. } 2004\end{array}$ & $\begin{array}{l}\text { "England is a country that 'dare not } \\
\text { speak its name" " - Daily Telegraph } 17 \\
\text { Oct. } 2004\end{array}$ & $\begin{array}{l}\text { "The rich hit the road" } \\
\text { - The Economist } 19 \text { June } \\
2004\end{array}$ \\
\hline
\end{tabular}


three categories of headlinese present some degree of reader accessibility challenge, the last clearly exemplifies the epitome of the sub-genre under analysis and may be compared to the anaphoric approach of "blind headlines" used in advertising where title comprehension is subjected to prior reading of the body copy.

\subsection{Sources of headlinese opacity}

Headlinese opacity has different origins which may be broadly summarised as being linguistic, cultural or contextual.

\subsubsection{Linguistic sources}

47 The question of linguistic headlinese opacity is directly linked to newspaper readership. Fifty-five per cent of the adult population of Great Britain read at least one national daily. ${ }^{6}$ Defining the readership profile of British mainstream newspapers is an undertaking beyond the scope of this study and consequently, we limit this aspect to a few preliminary remarks relative to readers' linguistic profile.

Speech accommodation theories have demonstrated that addressers accommodate speech to that of the audience targeted. Headlines are no exception to the rule and are consequently designed to target a broadly identified community of readers. Understanding readership expectations are, for Dor (2003: 696), just as important as understanding the information presented, "[C]onstruction of a successful headline requires an understanding of the readers - their state-of-knowledge, their beliefs and expectations and their cognitive styles - no less than it requires an understanding of the story." Consequently, newspapers and media research centres regularly commission surveys to balance what Randall (2000: 18) calls "an anecdotal knowledge of what their readers want" to determine the profile of their readers. However, the data is fragmented and/or orientated, as, for example, the regular MORI polls regarding the political orientations of The Guardian's readership.

49 A more general source of data is the conventional 6-category classification, commonly known as "the ABC scale", used by newspapers to identify the socio-economic status of their mainstream readership.

Table 4. The ABC Scale: categorisation according to $\mathrm{NRS}^{7}$ social grades

\begin{tabular}{|l|l|l|}
\hline A & Upper middle class & High managerial, administrative and professional positions \\
\hline \hline B & Middle class & Intermediate managerial, administrative and professional class positions \\
\hline C1 & Lower middle class & Clerical, junior managerial and administrative positions \\
\hline C2 & Skilled working class & Skilled manual workers \\
\hline \hline D & Working class & Semi- and unskilled workers \\
\hline \hline E & Lower class & State pensioners, widows, casual workers, etc. \\
\hline
\end{tabular}

Source: NRS Social Grades <http://nrs.co.uk/lifestyle.html> 

marketing and advertising objectives than to socio-cultural categories as evidenced by the fact that "widows", a category that would normally cut across all socio-economic categories, are relegated to E classification as "Lower class".

Concerning reception, and in spite of such shortcomings, the so-called "ABC1" categories that most British newspapers strive to reach does permit certain cautious generalisations regarding socio-cultural status of the targeted readership and allows us to posit that the newspaper's "favoured conception of readership", as Crystal (1995: 380) puts it, occupies high, intermediate and junior managerial and administrative positions and may be considered to be "college-educated laymen" possessing native or near-native competence of English. readers' linguistic profiles, that journalists use the language without any concessions: they write English for a public they presume to possess native command of the language with no attempt at linguistic "dumbing down" to facilitate possible alloglot readership access to content. Hence, headlines such as The Financial Times' March 7, 2007 "Stand-off over worker rights offers litmus test on trade" do not qualify as headlinese since they are not intended to generate incomprehension and, as such, offer little resistance to the newspaper's targeted readership.

Placed in the framework of Gotti's (2005: 25-26) characterisation of three types of specialised communication - peer-to-peer, specialists to non-specialists (educational purposes, academic textbooks, etc.) and specialised concepts expressed in everyday lexicon - headlinese discourse uncompromisingly situates itself in the peer-to-peer realm of communication.

Another point to be made with regard to linguistic sources of opacity is that, since newspaper discourse targets a native or near-native English-speaking readership, linguistic sources of opacity are not based on assumptions of lexical or syntactic difficulty per se but on what may be termed as a deviant use of language. As sub-editor Don P. Brown suggests in his online recommendations on producing good headlines, "The most effective headlines are those that give old cliches a new twist. Readers are familiar with the cliche, but something different about it will reel them in." One such example is The Times 23September 2005 headline, "Taking a screwdriver to the truth", where, by artful use of the highly contextualised "screwdriver" to replace the semantically close and attested "hammer", the journalist succeeds in rendering an otherwise familiar term unfamiliar to even the most proficient of native readers.

To conclude with this point, reader inaccessibility here is not related to monoreferentiality as would be the case in specialised scientific discourse (Gotti, 2005: 34-35), for example, where the semantic uniqueness of the term and its highly contextualised denotation are sources of opacity for the uninitiated. In the case of headlinese, it is, on the contrary, polyreferentiality and the highly decontextualised and connotative use of the term which are cultivated to generate reader inaccessibility.

\subsubsection{Cultural sources}

56 A primary culture-related factor to be taken into consideration concerns the degree of correlation between the "national" culture of the newspaper and that of its readership. This is particularly relevant in the case of Britain, a country with a widely multicultural 
population but which nevertheless boasts probably the world's largest number of national newspapers 8 (nine majors: The Daily Express, The Financial Times, The Guardian, The Daily Telegraph, The Independent, The Daily Mail, The Mirror, The Sun, The Times), as compared to the United States, for example, (two official, The Wall Street Journal and USA Today, and two de facto, The New York Times and The Washington Post). Given this paradox, may we assume what Develotte and Rechniewski (2001) call "a widely disseminated cultural knowledge"?

French linguist Gallisson (1995) suggests one approach to the question. Speaking in the context of decoding French newspaper and advertising headlines, Gallisson proposes the concept of "palimpsestes verbaux culturels" with regard to defining common "national" culture and newspaper readership. According to Gallisson's theory, PVCs, as he calls them, are lexical items, which, like palimpsests, encode multi-layered levels of culturally implicit references which are decoded - or not - according to the reader's degree of cultural integration into the mainstream fabric of society:

$\left[\mathrm{C}^{\prime}\right]$ est la référence à une mémoire collective, à un fonds commun, à une culture partagée par le plus grand nombre, qui valorise [...] tout ce qu'elle touche, alors qu'elle est composée de savoirs qui n'ont rien d'extraordinaire et encore moins de savant. Si la culture en question, toute mitée de "prosaïsme» et d'acquis épidermiques, joue un rôle qui la dépasse un peu, c'est qu'elle est bien davantage un signe de reconnaissance, un emblème d'appartenance, un facteur de cohésion sociale, qu'une somme de connaissances systématisées. (1995: 106) ${ }^{10}$

The question of a newspaper's cultural embedding is particularly significant in the case of international newspapers and weeklies. Despite the existence of different geographic editions targeting readership in different parts of the world, The Economist, for example, in spite of its large American readership,remains undeniably British in language and culture. Time Magazine, Newsweek and The Herald Tribune, on the other hand, are clearly linguistically and culturally stamped as American.

If a loosely defined common "national" cultural referential defined along the lines of Gallisson's "palimpsestes verbaux culturels" may be assumed, other potential areas of cultural deficit relate to specific domains and cover both classical culture ("Sondheim's 'inaccessible' piece wins Olivier" - The Daily Telegraph, 19 February 2007), or, in a broader, ethnological acceptance of culture, to specialised or professional domains ("Should Crufts be banned?1" - The Daily Telegraph, 7 March 2007), or finance (“Vulture funds' circle but debtors remain a moving target" - The Financial Times, 19 February 2007, or again "Googled by Microsoft" - The Financial Times, 7 March 2007).

\subsubsection{Context}

As van Dijk (1988: 144) states, "[H]eadline interpretation is not only a syntax problem but also a knowledge problem." Headline discourse relies heavily on the assumption of presuppositions, the shared knowledge between interlocutors. As a result, headlines such as "Cash-for-honours inquiry will drag on to blight Blair's final weeks in office" (The Times, 7 March 2007) or "Minister in climb-down over junior doctor fiasco" (The Daily Telegraph, 7 March 2007), however opaque they may appear to readers unfamiliar with current events in Britain, are easily accessible for the readers targeted by the newspapers in question due to presumed presupposition regarding their knowledge of current events in the country. 
61 In the case of headlinese, however, possessing the necessary content schemata does not guarantee access to meaning since headlinese mystification thrives on its autonomous textual status and context-free presentation. Comprehension resistance is greatly lowered when the headline is replaced in the textual architecture of the full deck whose function is precisely that of neutralising the obscurity of the headline by providing the contextualisation necessary to facilitate access. This game of checks and balances is clearly illustrated by the elliptical 24 February 2007 The Economist headline, "Pasta and fries", which loses much of its mystique when replaced in the highly contextualising architecture of its full deck:

Italy

Pasta and Fries

Italian anti-Americanism costs Romano Prodi his job

62 To conclude with cultural and contextual deficit, the point we would like to underline is that while cultural and contextual deficit are analogous in that they both result from the absence of relevant pre-existing content schemata, they differ fundamentally in that contextual deficit in the case of headlinese is artificially and artfully created with the express purpose of generating incomprehension and confusion. This holds equally true for areas not habitually requiring any specialised domain knowledge, as in the case of "No more bobbin' for the red, red robin" (The Guardian, 9 March 2004), as it does for the case of readers who do possess the necessary specialised knowledge, but are deprived of immediate accessibility due to cultivated and calculated opacity, as in the case of the legendary sports headline mentioned earlier, "Super Calley Go Ballistic Celtic Are Atrocious" (The Sun, 2000).

\subsection{Headlinese as shared discourse}

63 Given that the basic premise of headlinese is a capacity to generate opacity and subsequent incomprehension, the question as to it being a form of discourse shared by addressers and addressees alike arises. The conventional approach to the concept of discourse community posits that discourse, however technical, specialised or arcane, draws the boundaries that separates "insiders" from "outsiders" and forms the glue that binds "insiders" (addressers and addressees) together. In an orthodox perspective, "shared" discourse is thus to be taken as discourse whose linguistic and propositional dimensions are commonly understood by all members of the discourse community. Generic headlines may be said to conform to this conventional view of shared discourse with respect to the linguistic specificity and informative function by which they are characterised.

The calculated linguistic opacity of headlinese precludes the concept of shared discourse on a purely linguistic level. The shared dimension of this discourse lies in its focus on text as a perlocutionary speech act and its engagement with the reader's interpretative processes. This complicit interpretative challenge which binds addressor and addressee is the element commonly recognised, expected and shared by all members of the headlinese discourse community, as suggested by Candlin and \& Hyland (cited in Gotti 2005: 24): "[I]ndividuals write as community members and the specific properties of writing are seen as reflecting, and in part constituting, the interactions between members of the social groups." Gallisson (1995) sums up this special notion of "shared discourse" with his inimitable panache: 
Ce sur-codage [...] est à la fois une marque de connivence, un clin d'œil complice, un brouillage sélectif. C'est donc ce qui donne aux interlocuteurs le moyen de se reconnaître, de baliser leur espace de communication. C'est aussi ce qui permet à l'émetteur de faire basculer le récepteur dans son camp, de le manipuler (il est suggesteur, l'autre suggesté), de le fidéliser au discours qui lui est tenu, en le dissuadant de zapper, de décrocher avant d'avoir trouvé la solution de ... l'énigme. Et lorsqu'il l'a trouvée, satisfait de l'image positive de lui-même que sa réussite lui renvoie, flatté dans son orgueil, le destinataire se trouve dans de bonnes dispositions pour s'imprégner au mieux du message suractivé qu'on lui présente. $(1995: 106)^{12}$

Examined in the framework of Grice's Co-operative Principle, and his distinction between "flouting" (the addressee is expected to be sufficiently familiar with the context to access the message in spite of it not being consistent with the four maxims), and "violation" (the addressee is not expected to understand the message), we arrive at the conclusion that if headlines may at times "flout" the maxims, headlinese is a form of discourse that systematically endeavours to "violate" them and in so doing, paradoxically, adheres nevertheless to the Co-operative Principle by producing a form of discourse expected by the members of the discourse community concerned.

\section{Headlinese and discourse community}

Discussion of headlinese as a distinctive sub-genre of headlines raises the correlated question of identifying and characterising its readership and determining its status as a discourse community. To do so, we shall once again refer to Swales (1990) and his discussion of discourse communities. Even though his analysis focuses principally on academic research, Swales is careful to point out that his theories may be applied to other domains such as an association of stamp collectors or café owners, even if the latter do not belong to any formally constituted body.

\subsection{Speech and discourse communities}

67 Speech community and discourse community are closely related terms whose distinguishing features are not always clear. For Swales, if both speech and discourse communities may initially be defined around the notion of "[...] shared linguistic forms, shared regulative rules and shared cultural concepts [...]" (1990: 24), they differ in that they fulfil two different functions. The notion of speech community, for Swales, concerns a sociolinguistic grouping defined by social needs, whereas a discoursecommunity is defined in terms of sociorhetorical needsthat are essentially functional. Additionally, Swales distinguishes the two concepts through manner of admission. A speech community acquires its members through "birth, accident or adoption" whereas the members of a discourse community are recruited by "persuasion, training or relevant qualification" (1990: 24). A further distinction between the two language-use communities concerns Swales' apprehension of a speech community as being centripetal - i.e., assimilating people into the community - and a discourse community as being centrifugal - i.e., fragmenting people into groups according to specific domains of interest. Speech communities may therefore be considered to evolve in an inclusionary ethos while discourse communities tend to demarcate their special interests and evolve in an exclusionary ethos. ${ }^{13}$ 

inheritance or acquisition - to the cultural dimension of headlinese discussed above. Owing to the complex nature of the headlinese sub-genre, it is difficult to draw the line between inheritance and acquisition. Familiarity with the sub-genre as a common cultural artefact, if it may be regarded as providing an edge over the non-initiated, does not necessarily posit for expertise in the area, a condition comparable to lay knowledge of a particular field. Inversely, a reader with the necessary language skills may, over time, acquire the cultural, conceptual and contextual content schemata to accede to the pragmatic savoir-faire as in the case of conventional discourse communities defined by Swales (1990: 9): "The acquisition of genre skills depends on previous knowledge of the world, giving rise to content schemata, knowledge of prior texts, giving rise to formal schemata, and experience with appropriate tasks." In view of this ambiguity, we suggest that headlinese membership admission be considered a hybrid combination of "nature and nurture", the language component referring to the "nature" dimension and the interpretative skills to the "nurture".

\subsection{Swales' 6-point definition of discourse community}

70 Swales (1990: 25-27) further refines the concept of discourse community through a 6point scale according to which a discourse community (1) has a broad set of common public goals; (2) has mechanisms of intercommunication among its members; (3) uses its participatory mechanisms primarily to provide information and feedback; (4) utilises and hence possesses one or more genres in the communicative furtherance of its goals; (5) has acquired some specific lexis; (6) has a threshold level of members with a suitable degree of relevant content and discoursal expertise. The correlation between these criteria and the community of writers and readers of headlinese that we are attempting to define is fairly high.

71 Swales begins by positing that a discourse community must have "a set of common public goals", whether formal or tacit (1). It is clear that the discourse community we are trying to define does not function along the lines of a formally structured and regulated organisation as scientific discourse communities or other more leisureorientated ones do. Given the non-codified nature of the exchanges, whether the members even recognise themselves as a community is a moot point. The activities of this discourse community are, nevertheless, public and, as will be seen later, related to goals which may be described in terms of reporting and evaluating.

72 Let us begin by examining the criterion regarding "a threshold number of members with a suitable degree of relevant content and discoursal expertise" (6). In the context of the headlinese discourse community, two categories of members are clearly identified, the journalists who produce the text and the readers whom they target. 
Intercommunication between the two groups of the community is quasi inexistent. This is not in itself unusual as most media communication is characterised by onedirectional flow or the syndrome of "It is the few talking to the many" as Bell (1993:1) phrases it. Nonetheless, addressor/addressee interaction does exist - albeit in a limited form which is necessarily deferred, often indirect and not always verbal - and expresses itself through several channels. The "Letters to the Editor" column represents the traditional forum for expression of readers' views, even if limited to one column and deferred. Another form of feedback is inter-media metadiscussion in the form of communication on newspapers by other media such as radio and television talk show programmes. And finally, there is always the ultimate expression of reader disagreement with a newspaper story exemplified by the words, "[...] I hereby wish to cancel my subscription."

The headlinese discourse community, however, does not possess even this limited form of intercommunication between producers and receivers of text. Perhaps due to the plurality and anonymity of headlinese creation, readers do not call upon newspapers to explain or justify headlinese. Intercommunication in the headlinese discourse community does, nevertheless, exist but it is essentially of a lateral nature, restricted to and amongst peers, i.e., the readers. This intercommunication is reactive, interactive and cross-cultural, as we shall see in the following paragraphs.

Regarding the capacity of members to utilise and hence possess one or more genres in the communicative furtherance of their goals, given the different categories of headlinese discussed above, members do utilise and possess one or two genres (4). In the same vein, it is clear that members communicate through and about a discourse composed of characteristic lexicon and syntax (5). Similarly, Swales' notion of varying levels of discoursal maturity among members, establishing a hierarchical pyramid according to "seniority", may be applied to both addresser and addressee members of the community, according to the varying capacity to produce complex headlinese and the correlated capacity to decode it. As Don P. Brown states from his own experience as copy-editor at The Oklahoman, "Continuity leads to better headlines; one must write them day after day to get good at it." Presumably, the same applies to the readers.

Finally, concerning the "mechanisms of intercommunication among its members" (2) and the use of these as "participatory mechanisms primarily to provide information and feedback" (3), the headlinese discourse community may be said to possess very powerful "mechanisms" indeed in the form of the media themselves whose interest in "inter-media" metadiscourse translates into radio and television programmes which comment on the print press, and vice-versa, on a daily and weekly basis either in the form of press commentary or audience participative "phone-in" programmes. Either way, newspaper headlines are a low-cost support that generates high-ratings for such programmes. The Channel 4 radio programme in Britain, The Big Breakfast, and its special programme, Pun Down, provides an example of one such platform of intercommunication. The programme, which ran from 1992 to 2002, invited listeners to phone in with suggestions for "Pun of the Day" from the day's newspaper headlines and, on Fridays, proposed The Pun of the Week from the week's headlines, with an annual Headline of the Year in which context "Super Calley go ballistic Celtic Are Atrocious" was voted Pun of the Year for 2000. discussion platforms available for members of the headlinese discourse community. 
The focus of the exchanges is both informative (reporting and sharing discovery, providing samplings), and evaluative (criticising, classifying and assessing) as attested by the fact that a large number of these websites are devoted to proposing and voting for different categories of headlines as, for example, Headline of the Year, Headline of the Day, Sports Headline of the Year, The Most Absurd Headline of the Year, The Entertainment Headline of the Year, The Politics Headline of the Year, The Most Ludicrous Headline of the Year, The Greatest Tabloid Headlines Ever Written, Incorrect Headlines, and so on.

To conclude on this point, it is important to underline that while the headlinese discourse community admittedly suffers from a lack of formal status and recognition due to the absence of codified, regulated and institutionalised representative bodies, the potential of its communicative platforms, the size of the community's membership and the effervescence of its activities makes it an exceptionally dynamic one.

\section{Conclusion: journalistic or cryptic discourse?}

Headlinese is considered to be a genre found predominantly in Britain or Britishinfluenced countries. Thus the same penchant for headlinese is to be found in Australia, New Zealand, Canada and India, but is noticeably less present, for example, in French, ${ }^{14}$ German or Italian journalistic traditions. Hence, if headlinese is not a culture-specific sub-genre, its widespread prevalence in Britain does allow for it to be recognised as a characteristic trait of British journalistic tradition.

In conclusion, we would like to broaden the scope of the discussion by comparing journalistic headlinese to another highly codified "textual artefact" also regarded as a predominantly British genre and which presents a number of characteristics in common with journalistic headlinese: the cryptic crossword.

Though often present in other British-influenced countries - with the surprising exception of the United States where cryptic crosswords are an occasional feature and that in a limited number of newspapers - the cryptic crossword is considered a quintessentially British passion. South African journalist Sandy Balfour (2003) describes cryptic crosswords in his book on the genre, Pretty Girl in Crimson Rose: a Memoir of Love, Exile and Crosswords, as "The great British obsession" and the BBC Radio 4 website claims the genre as part of British national identity:

The crossword is generally regarded as a British institution, if not a British disease and has even been described as 'the unacknowledged conscience of our time' (<bbc.co.uk/radio4/factual/prettygirl.html)).

81 Cryptic crosswords share many linguistic features with headlinese, some of which are homophones, deletions, punning, concision, etc. However, it is the pragmatic nature of the two genres which presents interesting similarities.

An initial parallel may be drawn between the generic headline and the quick (noncryptic) crossword clue: both adopt the semantic approach and privilege the informative function, as exemplified by Daily Telegraph's Herculis general knowledge crossword with clues such as, Day nursery for young children and babies (6) or Ancient megalithic monument in $S$ England (10). ${ }^{15}$

83 In contrast, headlinese and cryptic crossword clues both privilege the pragmatic approach, calling for high interpretative skills and active reader interaction with the 
text. The following extract from the online Introduction to Cryptic Crosswords sums up the essence of both headlinese and cryptic crosswords:

Cryptic crosswords are widely considered the ultimate challenge for lovers of wordplay. [...] The word cryptic is defined by Chambers as 'hidden; secret; unseen; mysteriously obscure'. Clues in cryptic puzzles are just like that. To understand them, they have to be read in a very devious way. What the clue appears to be defining on the surface is designed as a distraction and is almost never what it really means. However, to be fair, the clue will always tell you what the answer is (usually more than once), even if you have to twist your brain inside out to read the clue in the way that tells you. A cryptic clue usually has a second part as well, called the subsidiary indication. This also leads you to the word but it does so using devious wordplay. (<www.crosswordtools.com/cryptic-crosswords.php>)

In view of the high correlation between the two genres, a better comprehension of the genericity of headlinese is perhaps to be gained by operating a paradigm shift whereby headlinese is distanced from its tenuous link with journalistic news discourse genericity and affiliated to genres reflecting a more entertainment and culture-specific orientation centring on the ubiquitous British passion for challenging wordplay:

We take considerable enjoyment from pulling words apart and reconstituting them in some novel guise, arranging them into clever patterns, finding hidden meanings in them, and trying to use them according to specially invented rules. Word puzzles and competitions are to be found in newspapers, at house parties, in schools, on radio and television, and in all kinds of individual contexts-such as when a commuter completes a crossword, or a child plays a game of Hangman. [...] There are thousand of possibilities, providing an almost inexhaustible series of topics for radio and television game shows, as well as feeding the insatiable demand for new domestic indoor pursuits. (Crystal, 1995: 396)

\section{BIBLIOGRAPHY}

Ariel, Mira. 1988. "Referring and accessibility". Journal of Linguistics 24, 65-87.

Balfour, Sandy. 2003. Pretty Girl in Crimson Rose: A Memoir of Love, Exile and Crosswords. London: J. P. Tarcher.

Bell, Allan. 1993 [1991]. The Language of News Media. Cambridge, MA: Blackwell Publishers.

Bell, Allan and Peter Garrett. 2001 [1998]. "Preface”. In Bell, Allan \& Peter Garrett (eds.), Approaches to Media Discourse. Oxford: Blackwell Publishers, 3.

Breure, Leen. 2001. "Development of the genre concept”. Retrieved March $2007<\mathrm{http}: / /$ www.cs.uu.nl/people/leen/GenreDev/GenreDevelopment.htm>.

Brown, Don P. and Doug Simpson. 2002. "How to write good headlines". Retrieved July 2011 $<\mathrm{http}$ ://www.apwuiowa.com>. 
Crystal, David. 1987. The Cambridge Encyclopedia of Language. Cambridge: Cambridge University Press.

Chovanec, Jan. 2003. "The mixing of modes as a means of resolving the tension between involvement and detachment in news headlines". Brno Studies in English <http://dkf.ics.muni.cz/ xvalicek/journal/ff_bse/viewarticle.php>.

Develotte, Christine and Elizabeth Rechnieweski. 2001. "Discourse analysis of newspaper headlines: a methodological framework for research into national representations". The Web Journal of French Media Studies 4/1, Retrieved May 2005 <http://wjfms.ncl.ac.uk/titles.htm>. Dor, Daniel. 2003. “On newspaper headlines as relevance optimizers". Journal of Pragmatics 35, 695-721.

Gallisson, Robert. 1995. "Les palimpsestes verbaux : des actualiseurs et révélateurs culturels remarquables pour publics étrangers”. Études de linguistique appliquée 97, 104-128.

Gattani, Akshay. 2005. Maximum Entropy Discriminative Models for Headline Generation Retrieved March, 2007 <http://www.natland.cs.sfu.ca./researchProject.php>.

Gotti, Maurizio. 2005. Investigating Specialized Discourse. Bern: Peter Lang.

Grice, Paul. 1989. Logic and Conversation. Cambridge, MA: Harvard University Press.

Hagerty, Bill. 2005. "Media: The tabloids and the headlines that say it all”. Independent on Sunday, July 31.

Halliday, M. A. K. 1967. Grammar, Society and the Noun. London: H. K. Lewis for University College, London.

Herino, Micheline and Shaeda Isani. 1994. «Quel(s) domaine(s) langagier(s) pour une évaluation en compétence en langue? ». ASp 5-6, 249-256.

Kress, Gunther and Theo van Leeuwen. 2001 [1998]. "Front Pages: (The Critical) Analysis of newspaper layout”. In Bell Allan \& Peter Garrett (eds.), Approaches to Media Discourse. Oxford: Blackwell Publishers.

Kronrod, Ann and Arit Engel. 2001. "Accessibility theory and referring expressions in newspaper headlines". Journal of Pragmatics 33, 683-699.

Mardh, Ingrid. 1980. Headlinese: On the Grammar of English Front Page Headlines. Malmö, Sweden: cWK Gleerup.

NRS Social Grades <http://nrs.co.uk/lifestyle.html>

Randall, David. 2000 [1996]. The Universal Journalist. London: Pluto Press.

Swales, John. 1990. Genre Analysis. Cambridge: Cambridge University Press.

Van Dijk, Teun A. 1988. News as Discourse. Hillsdale, NJ: Lawrence Erlbaum Associates, Publishers.

\section{NOTES}

1. A British television series called "Absolutely Fabulous".

2. The fourth maxim, quality i.e., truth, is too moot a point to be taken into consideration with regard to journalism. 
3. The first refers to the sinking of the Argentinean warship, General Belgrano, by the British navy during the Falklands War; the second to the introduction of the ECU under Jacques Delors' leadership of the EU; the third to the defeat of the Glasgow Celtics by Inverness Caledonian ("Calley") Thistle in the 2000 Scottish Cup finals; it is a parody of the famous "Supercalifragilisticexpialidocious" in Mary Poppins.

4. The full deck offers a little more insight: Urban music and gays - Mobo phobic-Homophobic reggae music comes to Britain; Sovereignty over the Arctic - Breaking the ice - Everyone wants a piece of the Arctic

5. Newspaper headline after a public transport workers' strike on a Monday

6. A distinction is to be drawn between circulation and readership. Readership is always higher than circulation since a newspaper, while bought by only one person, is generally read by more than one.

7. NRS: National Readership Survey

8. According to the figures reported in the 7 March 2007 issue of The Times, India probably comes a close second with no less than eight English-language national dailies.

9. "Verbal cultural palimpsests".

10. Loosely translated as: "[A cultural verbal palimpsest] is a reference generated by collective memory, common knowledge background, a culture shared by the largest number of people and related to elements which are neither extraordinary nor erudite. If this culture, made up as it is of prosaic and superficial elements, plays a greater role than would seem justified, it is because it is a sign of recognition, an emblem of belonging, a factor of social cohesion more than a sum of systematised knowledge.

11. Crufts: World's biggest dog-show organised by The Kennel Club UK.

12. Loosely translated as: "Such hyper-coding is a sign of connivance, a complicit wink, a form of selective encoding. It is what offers interlocutors a means of identifying each other and flagging their communicative territory. It is also what allows the addresser to win the addressee over (he is the "suggester" and the other the "suggestee") and gain adhesion to his discourse, to dissuade zapping and switching off before finding the solution to... the enigma. And when he does find it, satisfied with the positive self-image reflected by his success, flattered in his pride, the addressee finds himself well disposed to tackle the hyper-coded message he has been presented with."

13. Although exclusionary and inclusionary are, of course, to a large degree, the antithetic goals of the same finality.

14. Le Canard enchaîné being a noteworthy exception.

15. Respectively "creche" and "Stonehenge"

16. Answer: a newspaper

\section{ABSTRACTS}

Headline discourse and its genericity have traditionally been the focus of lexical- and syntacticorientated analysis. In a departure from the purely linguistic approach, this article analyses British headline discourse from a pragmatic perspective with a view to establishing the existence of a sub-genre the rhetoric specificity of which is measured against proven pragmatic and genre analysis theories. The highlighting of the essentially pragmatic aspect of headline discourse, which calls upon the reader to engage and interact with text and socio-context, leads us to 
suggest it possesses closer affiliation to the cryptic crossword, another quintessentially British genre, rather than to conventional journalistic headline discourse essentially designed to inform.

Le discours et la généricité des titres à la une de la presse britannique ont fait l'objet d'une approche essentiellement lexicale et syntaxique. Cet article s'en démarque en proposant une analyse pragmatique en vue de dégager l'existence d'un sous-genre à part entière défini par une spécificité rhétorique dont la validité générique est mesurée à l'aune des théories relevant des domaines de l'analyse pragmatique et du genre. Cette mise en lumière de la visée pragmatique de ce type de discours où le lecteur est appelé à engager et interagir avec le texte et le sociocontexte, nous conduit à le distancier du genre purement journalistique à visée informative en proposant son rapprochement avec un autre genre à spécificité britannique, les mots-croisés cryptés.

\section{INDEX}

Keywords: crosswords (cryptic), genre analysis, headline, headlinese, journalism, pragmatic analysis

Mots-clés: analyse de genre, analyse pragmatique, journalisme, mots-croisés (cryptiques), titre d'articles de journaux

\section{AUTHOR}

\section{SHAEDA ISAN}

Shaeda Isani est professeur des universités à l'UFR des langues, Université Grenoble 3 (France). Membre de l'ILCEA-Gremuts, sa recherche porte sur les langues et cultures de spécialité (droit et affaires).shaeda.isani@u-grenoble3.fr 